Derleme Makale

\title{
Sı̆̆ır Yetiştiriciliğinde Stressiz ve Güvenli Sı̆̆ır Yönlendirme
}

\author{
Serap GÖNCÜ*
}

\begin{abstract}
Özet
Hayvan davranışlarına ait bilgiler hayvanlarla çalışmayı kolaylaştıran, stresi azaltan, hem hayvan hem de hayvanla çalışan kişilerin güvenliğini sağlayan temel noktaları içermektedir. Bir hayvanın "Güvenlik Bölgesi", bir hayvanı çevreleyen alan olup insan dahil olmak üzere potansiyel bir avcı ya da tehditle kuşatıldığında kaçmasına neden olan mesafedir. Hayvancılık işletmelerinde hayvanların bir yerden bir yere götürülmesi gerekiyorsa, öncelikle hayvana ait "Bireysel Güvenlik Bölgesi" (BGB), "denge noktası" ve "kör nokta" terimlerinin anlaşılması gerekir. İşletmenin karlılığı ve sürdürülebilirliği özellikleri, teknolojik alt yapısı, çalışan ve hayvan açısından ergonomik yapı, personelin beceri düzeyi, iş tanımı ve işlerin organizasyonu, uygulamalar ile doğrudan bağlantılıdır. Bir işletmede hayvanlara bakım ve uygulamalar sırasında hayvana yaklaşım şekli kayma, düşme, elektrikli uyarıcı kullanımı, sesliliğin artması gibi belirtilerle değerlendirilebilir. Hayvanla temas kaynaklı yaralanmalar değişen düzeylerde kayıplara neden olmaktadır. Yaralanma sonrası, tedavi masrafları ve iyileşme süreci de etkiyi artırmaktadır. Yapılan çalışmalarda çalışanların tekme, boynuz veya baş gibi darbe alma oranı $\% 67$ ile \%87 arasındadır. Bu konular dikkate alındığında, hayvansal üretimde stressiz ve güvenli sürü yönetimi için gerekli olan temel bazı bilgilerin derlenmesi faydalı görülmüştür.
\end{abstract}

Anahtar Kelimeler: Stressiz, güvenli, sürü yönetimi, hayvancılık

\section{Stress-Free and Safe Handling in Cattle Management}

\begin{abstract}
Information on animal behaviour includes the key points that ensure the safety of people who work with animals, reduce strain and work with animals. "Flight Zone" is the area surrounding an animal, the distance that causes alarm and escape behavior if it is surrounded by a potential hunter or threat, including humans. If animals need to be transported from one place to another, firstly the animal's behaviour characteristics such as " Flight Zone" (FZ) and "balance of point" and " blind spot" must be understood. The cattle farm sustainablity and profitablity strongly depend on farm technological infrastructure, ergonomic conditions in terms of employee and animal t, the technical knowledge of personnel, the job description and organization of the works, the work routine and environment are linked with production levels. In an enterprise, cattle care level can be identified by scoring, falling, electrical prod use and vocalization. Injuries caused by animal contact cause mild to severe loss depending treatment costs and healing process.Itt is reported that the rate of contact with the animals such as kick, horn kick or head kick is very high between $67 \%$ and $87 \%$. Therefore, this study aims to review some basic information necessary for stress-free and safe cattle handling.
\end{abstract}

Key words: Low stress, safe, herd management, livestock

ORCID ID

0000-0002-0360-2723

Yayın Kuruluna Geliş Tarihi: 15.05.2019

Kabul Tarihi: 21.08.2019

${ }^{*}$ Çukurova Üniversitesi, Ziraat Fakültesi, Zootekni Bölümü, Adana

E-mail: serapgoncu66@gmail.com 


\section{Giriş}

Hayvan davranışlarına ait bilgiler hayvanlarla çalışmayı kolaylaştıran, stresi azaltan, hem hayvan hem de hayvanla çalışan kişilerin güvenliğini sağlayan temel noktaları içermektedir (Grandin, 1989; Albright, 2004; Göncü 2018). Hayvan davranışları; hayvansal üretimde hayvan refahı temini, kontrolü, stressiz ve güvenli sürü yönetimi konusunda en önemli göstergeleri sunan bilim dalıdır. Yaralanmalar hayvancılık işletmelerinde sıklıkla karşılaşılan bir sorundur. Süt sığırcılığ 1 işletmeleri bu açıdan yüksek risk unsuru içeren üretim dalıdır. İşletmelerin donanım ve teknolojik alt yapısı, çalışan ve hayvan idaresi açısından ergonomik koşullar, personelin beceri düzeyi, iş tanımı ve işlerin organizasyonu, rutin kontrolleri, işletme ortam koşulları üretim aşamaları ile bağlantılıdır. Hayvansal temas kaynaklı yaralanmalar farklı düzeylerde kayılara neden olmaktadır. Yaralanma sonrası, tedavi masrafları ve iyileşme süreci de etkiyi artırmaktadır. Süt sığırcıllğı işletmesi çalışanları ve diğer canlı hayvan ile uğraşanlar genel olarak hayvanlarla çalışmanın tehlikeli olduğunun farkındadır. Çalışma ve bulundukları koşullar, hayvanların saldırgan olduğunu onlara zaman içinde bir şekilde göstermiştir. Ancak hayvanların neden saldırdığ 1 veya saldırı anında kaçmaktan başka yaklaşımlarla saldırıyı önleyebilecekleri konusunda teknik bilgileri ve sebep-sonuç tecrübeleri yoktur (Hemsworth ve ark. 2000; Göncü ve ark. 2017). Hayvancılık sektöründe görülen iş kazalarının çok önemli bir bölümü, hayvanlarla kurulan birebir fiziksel temastan kaynaklanmaktadır. Hayvanların çifte atması, itmesi, hırçınlaşarak saldırması ve 1sırması yaralanmalara neden olmaktadır. ABD'de The National Institute for Occupational Safety and Health (NIOSH) (NIOSH)'in 1993 yılında yaptığ göre tarımsal sektörlerde, yaralanmaların önemli bir kısmı hayvanlarla fiziksel temastan kaynaklanmaktadır. Sadece sığır ve koyun kaynaklı olaylar bunların \%18'ini teşkil etmektedir. Aynı zamanda bu yaralanmalar geçici iş görememe konusunda en çok işgünü kaybına neden olan olaylar olarak ortaya çıkmaktadır (Anonim, 2016). Göncü ve Koluman (2019) tarafindan hayvanla temas kaynaklı problemler konulu çalışmada çalışanların tekme, boynuz veya baş darbesi gibi hayvanlarla temas kaynaklı darbe oran1 \%67-87 arasında bildirilmektedir. Genel olarak bakıldığında, hayvancılık işletmelerinde çalışanlarda hayvan ve makinelerle çalışma kaynaklı çeşitli büyük yaralanmalar yaşandığı görülmektedir. Hayvanla temasta en riskli grubu büyükbaş hayvanlar oluşturmaktadır (Busch ve ark. 1986; Conrad, 1994; Sprince ve ark. 2003). Sığırlara bağlı kazalarda, ölümlerin hayvanın saldırgan davranışlarıyla ilgili olduğu gösterilmiştir (Ornehult ve ark. 1989). Ancak bu soruna katkıda bulunan diğer birçok faktör de söz konusudur. Hayvancilıkta günlük olarak yapılması gereken pek çok iş yaralanma riskini içermektedir. Yeni doğan buzağıların numaralanması, yemleme, boynuz köreltme, tırnak kesimi, sağım ve hayvanların bir yerden bir yere götürülmesi gibi işlemler yaralanmaların sıklıkla yaşandığ 1 uygulamalardır (Breuer ve ark. 2000; Lindsay ve ark. 2004; Wiggins ve ark. 1989). Ayrıca Lindahl ve ark (2016), çalışan, hayvan ve tesis özellikleri arası ilişkilerin önemli olduğunu bildirmiştir. $\mathrm{Bu}$ yaralanmalar için en büyük risk altındaki insanlar, mesleği veya geçim kaynağ büyükbaş hayvanları olan kişilerdir (Nogalski ve ark. 2007). Langley ve Hunter (2001), büyükbaş hayvanların (inekler ve atlar) çiftliklerdeki işçiler arasında ölümlerin $\% 67$ 'sine neden olduğunu bildirmektedirler. Çiftlik hayvanları genellikle insanlardan korkmalarıyla sonuçlanabilecek olumsuz muameleye maruz kalırlar. İnsanlardan korkma, hayvan refahını ve muhtemelen süt üretimini azaltabilir ve hem hayvanlar hem de bakıcılar için yaralanma riskini artırabilir. Ancak hayvanlarla olumsuz tecrübe yaşayan çalışanlarda daha sonraki uygulamalarında kendini koruma amaçlı olarak hayvanlara daha sert davrandıkları gözlenmektedir. Hatta sürüdeki bazı ineklerin huysuz ve saldırgan olduğu gerekçesi ile kesime gönderilmesi de yaygındır. Buna ek olarak hayvana uygun olmayan yaklaşımlar hayvansal ürünlerde de etkisini sürdürmektedir (Panea ve Ripoll, 
2018). Hayvansal üretim hayvana doğru yaklaşım ve yönlendirme ile yaralanma ve stressiz yönetim ile daha sağlıklı ürün elde edilmesi mümkün olmaktadır. Bir dizi yeni araç, ekipman, yöntem ve yönetim süreçlerinin geliştirilmesi ile üründe morarma, yaralanma ve kemik kırıkları nedeniyle kayıplar en aza inmektedir.

Ayrıca hayvanla mücadele sırasında barınak ve alet ekipmanların da zarar görme riski yüksektir. Oysa hayvan davranış özellikleri kullanılarak çalışıldığında yapılacak iş kolaylaşmakta ve stresi azaltarak daha kısa zamanda is tamamlanmakta hem hayvan hem de çalışan kişiler güvende kalmaktadır.

Tüm bu noktalardan hareketle, hayvansal üretimde hayvan refahı temini, kontrolü, stressiz ve güvenli sürü yönetimi için bilinmesi gerekli olan temel sığır davranış özelliklerine ait bazı bilgilerin derlenmesi amacıyla bu çalışma yapılmıştır.

\section{Güvenlik Bölgesi}

Bir hayvanın "Güvenlik Bölgesi", bir hayvanı çevreleyen alandır, insanlar dahil olmak üzere potansiyel bir avc1 ya da tehditle kuşatılırsa alarm ve kaçış davranışına neden olan mesafedir. Hediger (1955), güvenlik bölgesini, saldırı anındaki kaçış mesafesi, sürü içindeki mesafe ve sürü dişındaki diğerlerine karşı olan sosyal mesafe olmak üzere 3 gruba ayırmıştır.

Hayvancıllk işletmelerinde hayvanların bir yerden bir yere götürülmesi gerekiyorsa, öncelikle hayvana ait "Bireysel Güvenlik Bölgesi (BGB)" ile grup (sürü) halindeki hayvanlarda ki "Grup Güvenlik Bölgesi (GGB)" terimlerinin anlaşılması gerekir.

\section{Bireysel Güvenlik Bölgesi}

BGB, aslında bir hayvanın kendisini güvende hissettiği kişisel alanını tanımlamaktadır. Hediger (1955) ilk önce vahşi hayvanlarda bireysel güvenlik bölgesi prensibini tanımlamıştır. Kilgour (1971) ve Grandin (1989) de daha sonra koyun ve sığırlar için bireysel güvenlik bölgesi prensibini kullanarak hayvanlarin hareket ettirilebileceğini göstermişlerdir. 'Bireysel Güvenlik Bölgesi', hayvanın etrafında hayali çember demek olup bu çemberin içine girildiğinde hayvan yaklaşan kişiden veya canlıdan uzaklaşma eğilimi gösterir. Diğer bir deyişle yaklaşıldığında hayvanın uzaklaşma eğilimi gösterdiği mesafede oluşan çember 'Bireysel Güvenlik Bölgesi'ni ifade eder.

\section{Sürü Güvenlik Bölgesi}

Bir grup sığır, grubun etrafında "Sürü Güvenlik Bölgesi" içinde hareket ederler. Bakıc1 grubun güvenlik bölgesi içine girdiğinde sürü toplu olarak ortak hareket edecektir. Konum ve hareket ilkeleri, sürülerin yönetiminde de bir hayvana yaklaşım esasına göre uygulanır. Bir sürü doğru yönde ilerlerken, çalışan kişi "Sürü Güvenlik Bölgesi” sınırlarında çalışır. Sürü güvenlik bölgesi 45-60 derecelik hareket ettirme pozisyonuna sürü hareket durumuna göre girip çıkarak, sürüyü istenen hız ve yönde hareket ettirir.

$\mathrm{Bu}$ terimlerin bilinmesi ve sürü yönetiminde kullanılmas1 hayvan üzerindeki stresi ve yaralanma olasılığını azaltır.

\section{Güvenlik Bölge Çapı}

Bir ineğin BGB'si hayvana yaklaşımda çalışanın koruması gereken mesafeyi ifade eder. Çalışan hayvanın BGB içine girecek olursa inek hareket ederek o mesafeyi korumaya çalışır. Aynı şey sürü halinde hareket eden inekler içinde geçerlidir. Bir yetiştirici veya sığırla çalışan bir kişi sığırın bireysel emniyet bölgesi sinırları ve özelliklerini bilirse, sığırın sevk ve idaresinde zorlanmaz (Grandin, 1993).

Bireysel güvenlik bölgesinin, çapı hayvanın yabani veya evcil olmasina, sevk ve idare edenin yaklaşım tarzına, sığırın heyecanlanma durumuna ve içinde bulunduğu koşullara bağlı olarak değişim gösterir. Genel olarak sığırda bireysel güvenlik bölgesi yarıçap1, 1.5 ile $7.5 \mathrm{~m}$ arasında değişirken, açı alanda serbest dolaşan sığırlarda bu mesafe 90 m'ye kadar çıkabilmektedir (Albright, 1993). 


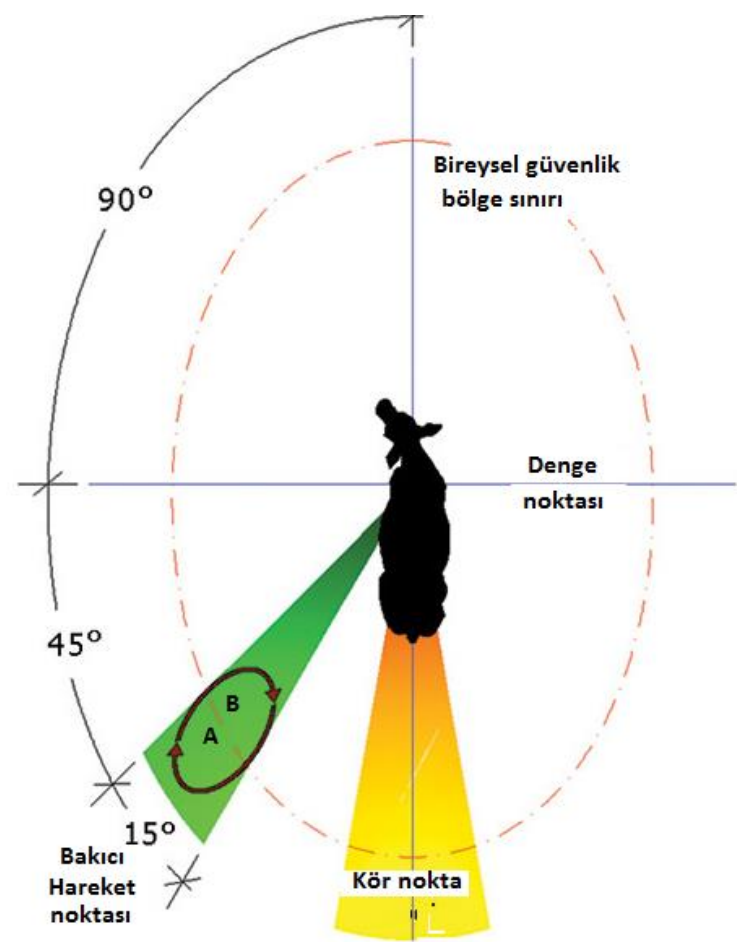

Şekil 1. Sığırda, bireysel güvenlik bölgesi, denge noktası ve kör nokta (Anonim, 2019)

Bazı işletmelerde ineklerin bireysel güvenlik bölgeleri ineklerin bireysel özelliklerine göre belirli limitler arasında değişirken özellikle sığıra iyi davranılan bazı işletmelerde sıfıra yaklaşabilmektedir. $\mathrm{Bu}$ farklılıktaki temel neden ineklerin daha önceki tecrübeleri ve bakıcıların ineklere olan davranışları olarak yorumlamak mümkünse de tamamen nereden kaynaklandığı henüz belirlenebilmiş değildir (Hagen ve Broom 2003). Bireysel güvenlik bölgesine tehdit algılayan inek bunu davranıșları ile karșısındaki canlıya ifade eder.

Hayvanın BGB dışında birisi durduğu zaman, hayvan dönerek, kişiyi görmeye ve niyetini anlamaya çalışır. Yaklaşan kişi BGB'ye yavaş, sessiz ve sakince girerse, hayvan benzer şekilde uzaklaşarak BGB sınırını korur. BGB'ye ani, hızlı ve kötü niyetli bir giriş olursa hayvan kendini korumak adına beklenmeyen davranışlar göstererek saldırabilir. Paniklenmiş hayvanların bir araya toplanarak korunmaya çalışması sadece yaklaşan kişilere değil sürü içinde özellikle küçük veya zayıf hayvanlarda yaralanmalara neden olabilmesi nedeniyle tehlikelidir.
Bir hayvanın BGB büyüklüğü, o hayvanın insanlarla yaşadığı deneyimlere göre değişim gösterir. Bireysel güvenlik bölge çapı, bazı durumlarda artmakta bazı durumlarda ise küçülmektedir (Göncü, 2018). Sığır bireysel güvenlik bölge sınırları içerisine birisinin gelmekte olduğunu fark ederse bölge çapı artmaktadır. Hayvana baş tarafindan yaklaşılırsa ve sığır heyecanlanırsa bireysel güvenlik bölge çapı yine artış gösterecektir. Bir diğer deyişle kişi uzak mesafede bile dursa hayvan hemen uzaklaşmaya çalışacaktır.

Sığır, dar bir geçit koridorunda ilerlediğinde veya arkasında duran bakıcı geri çekildiğinde sığır bireysel güvenlik bölgesi çap1 daralmaktadır. Ayrıca bir sığır insanın yanından geçiyorsa çap küçülmektedir. Ancak aynı hayvana yaklaşım şekli de hayvanın BGB sınırlarını değiştirir.

Ayrıca hayvanlar çalışma sırasında heyecanlanırlarsa, sakinleşmeleri için 20 ila 30 dakika beklemek gerekir. Sığır sürü hayvanı olup sürüdeki diğer hayvanlarla birlikte hareket etmeyi tercih eder. $\mathrm{Bu}$ nedenle genel olarak sığırı sürü halinde hareket ettirmek daha kolaydır. Sürü halinde hareket ettirmek için sürü büyüklüğüne göre 2 veya 3 kişinin birlikte çalışması gerekir.

\section{Denge Noktası}

Hayvana yaklaşımda bireysel güvenlik bölgesine ek olarak bilinmesi gereken denge noktası vardır. Sı ğırlarda denge noktası hayvanın omuzları üzeri olup kürek kemiği üst kısmına denk gelmektedir. Hayvanın burun ucundan kuyruğa doğru, sirtı boyunca dik bir çizgi olduğu varsayılırsa ve bu düz çizgiye omuz üstünden (kürek kemikleri hizasından) 90 derecelik açı ile yine hayali bir dik çizgi çizildiğinde omuzları üstünde kalan nokta denge noktasını meydana getirmektedir. $\mathrm{Bu}$ yer hayvanın omuz başından geriye doğru sağrı kemikleri yanında 45-60 derecelik alanda yer almaktadır (Grandin, 1989). Eğer omuz başından geriye bakan bir inek denge noktasının arkasında birini görürse ileriye 
doğru gider ve belirli mesafeden sonra tekrar bakarak kontrol eder.

Hayvanın bireysel güvenlik bölge sınırlarında sağ veya sol taraftaki denge noktasina girildiğinde, sığır giriş yapılan yönün aksi olmak üzere diğer yöne doğru hareket edecektir. Denge noktasının arkasına geçildiğinde hayvan ileriye doğru; denge noktasının önüne geçildiğinde ise geriye doğru hareket edecektir (Grandin, 1989).

Sığırlar, yaklaşan birini gördükleri zaman bu prensiplere göre hareket ederler. Ancak hayvana bağırma, vurma veya şok uygulaması hayvanın bireysel güvenlik bölgesini artırarak șiddet uygulamasına neden olabilir. İşletmelerde hayvanlarla direk çalışanların yaklaşımı hayvanın davranışlarını etkiler.

Bireysel güvenlik bölgesi ve denge noktası kavramlarını anlayan hayvancılık işletmesi çalışanları hayvanları daha kolay hareket ettirebileceklerdir. Ancak iş güvenliği açısından üzerinde durulması gereken noktayı ifade eden "kör noktayı" da hayvanla çalışmaya geçmeden önce anlamış olması gerekir. Çünkü sakin hayvanların yönetimi çok daha güvenli olmakta iş kısa sürede tamamlanmaktadır.

\section{Kör Nokta}

Sığırın burun ucundan sırt boyunca çekilen çizgi ile sağrı kemikleri arasında kalan kısım ise sığırın görüş mesafesi dışını yani "kör noktayı" oluşturmaktadır (Şekil 1). Sı̆̆ır 300 derecelik bir açı ile çevresini görme yeteneğinde olup bu açının dışında kalan 60 derecelik alan görüş mesafesi dişıdır (Grandin, 1989). Sığırın hemen arkasında yer alan bu kör noktadan uzakta durmak gerekir. $\mathrm{Bu}$ "kör noktada" herhangi bir hareket hayvanı huzursuz eder ve sinirlendirir. Eğer sığır orada ne olduğunu anlayamaz ise, kendini güvene almak için tekme atar. Sığır direk geriye tekme atan atların aksine ön taraftan başlayıp yan taraf ve arka olmak üzere geniş bir açı ile tekme atar. Buzağılar doğrudan geriye tekme atabilirler Tekme önleyici, bir ineğin meme veya arka bacaklarını kontrol etmeniz gerektiğinde kullanışlıdır. İneklerin ayrıca acı çeken taraflarına doğru tekme atma eğilimi vardır. $\mathrm{Bu}$ nedenle mastitis olmuş bir inek genel olarak mastitis olan tarafa kimseyi dokundurtmak istemez ve o tarafa tekme atar. $\mathrm{Bu}$ nedenle mastitis olan tarafin aksi tarafından yaklaşmak gerekir. Kızgınlık döneminde olan ineklerde hormonal değișim ve yeni buzağılamış olan ineklerde de annelik içgüdüleri nedeniyle daha saldırgan olabilirler. Ayrıca, hayvanlar sürüden uzaklaştırıldığında veya yabancı biri yaklaştığında da benzer durum söz konusudur (Ornehult ve ark.1989; Pickett ve ark. 1995)).

\section{Stressiz Hayvan-Sürü Yönetimi}

Hayvancilık işletmelerinde hayvanlarla sürekli olarak çalışmak zorunluluğu vardır. Boynuz köreltme, tırnak kesimi, sağım, tartım, ölçüm, yemleme ve hayvanların bir yerden diğer bir yere taşınması gibi birçok işlem yapılması gerekir. $\mathrm{Bu}$ uygulamalar bireysel olarak az sayıda hayvanla veya çok sayıda hayvanla birlikte çalışma şeklinde olabilmektedir. Tüm bu ișlemler eğer doğru yaklaşılmaz ise hem hayvan hem de insan için stres ve kayıp nedeni olmaktadır. Özelikle hayvan idaresi için kullanılan hayvan doğasına uygun özel tasarlanmış alet ekipmanların kullanılmadığ kayıplar daha da artmaktadır. Bu nedenle çiftlikler bu kayıpları minimize etmek için işlem yapmamayı tercih etmektedirler. Hayvanları yönlendirme ve bir yerden bir diğer yere götürülmesi aşamalarında ciddi problemler yaşanmakta ve hem çalışan hem de hayvan için stres kaynağı olmaktadır. Özellikle büyük entansif besi işletmelerinde hayvan tartımı yapılması karlılık açısından elzem iken bu zorluklar nedeniyle yapılamamaktadır. Oysa olması gereken o işlemlerin yapılmaması değil uygun yaklaşım ve teknik kullanarak stresi minimize edecek şekilde yapılmasıdır. Stressiz hayvan yönetimi için 3 yol vardır.

1. Hayvan doğasına uygun olarak yaklaşmak.

2. Hayvan doğasına uygun olarak tasarlanmış alet ekipman kullanmak.

3. Hayvan ulaşım koridorları inşası.

\section{Hayvan Doğasına Uygun Yaklaşım}


Hayvanları sakin tutmak ve kolayca hareket ettirmek için, çalışanın BGB sınırlarını iyi anlaması ve bu sinırı kullanarak hareketi yönetmesi gerekir. Hayvanların hareket etmesini sağlamak için

1. BGB sınırı içinde giriş yaparak hareketi başlatmak

2. BGB sınırından çıkarak hareketi durdurmak yeterlidir.

Stressiz sürü yönetimi hayvanı çok rahat bırakmak anlamında olmayıp hayvanı kontrollü düzeyde hareket ettirmek için BGB sınırlarının zorlanarak kullanılması gerekir. $\mathrm{Bu}$ nedenle hayvanın BGB sınırının doğru belirlenmesi çok önemlidir.

Sığırlar, gitmek üzere oldukları yöne bakarak ilerler. Bu konuda uzmanlar, bir hayvanın kafasının konumunu belirleyerek hangi yöne döneceğini tahmin edebilirler. Bir hayvanı döndürmek için hayvan bakıcılarının hayvan başını çevirecek şekilde pozisyon almaları gerekir. İyi bir bakıc1, sı ğırları bir sürüde sürekli olarak izler ve sığırların sürü önündeki ve kenarlarındaki baş hareketlerini fark ederek yön veya hizda düzeltme yapabilir. $\mathrm{Bu}$ nedenle, bakıc1 hayvan hareketlerini sürekli gözetim altında tutarak sorun oluşmadan önce uygun müdahalede bulunabilir.

Ahırdaki koridorların boyutları, şekli ve kullanılan malzeme hayvanların hareket şeklini ve yönünü etkilemektedir.

Sığır toplanma bölmelerine çok fazla hayvan alınması en yaygın hayvan yönetme hatalarından biridir. Kalabalık bölme ve koridorlardan çıkacak hayvanlar, tamamen boş veya çok dolu yerlere girmekte çekince gösterirler. $\mathrm{Bu}$ nedenle yarısı dolu bir alan temini hayvanların istenen yöne gitmesini kolaylaştıracaktır. Koridor sonundaki toplanma alanında hayvanlar çok sıkı bir şekilde itilirlerse, hayvan hareketleri stresli, hale gelebilir.

BGB sınırları içine çok fazla girilmesi sı ğırları çok rahatsız eder. Çalışanlar sığırın BGB'si içinde kaldığı ve uzaklaşmadığ zaman hayvanlar çok sinirlenir. O zaman sığır, geri dönüp, çalışanı geçip, daha geniş alana doğru kaçma davranışı gösterir. Hayvanlar geri dönmeye başlarsa, çalışan geri çekilmeli ve kendisi ile hayvanlar arasındaki mesafeyi arttırmalıdır. Geri çekilme, hayvanların geriye dönme belirtileri gösterdiğinde yapılmalıdır. Sürü halinde hareket eden bir sürü grubu bir şeylerden çekinir ve dururlarsa, sabırlı olup liderin çekindiği nesneyi algılayıp geçmesi için zaman vermek gerekir. Sürüdeki lideri takip eden diğer bireyler sadece lideri takip edecektir. Sürü halinde harekette iken sürüden ayrılan bir sığırı kendi haline bırakıp sakinleşmesini beklemek en güvenli yoldur. Onları yakalamaya, tutmaya çalışmak veya onlara vurmak saldırganlığı artıracaktır. Yalnız kalan sığır sakinleşir ve sürünün geri kalanına katılmak üzere harekete geçer. Çünkü sürüdeki tüm hayvanlar birbiri ile vücut dili konuşmakta olup göz temasını korumalar1 esastır. Sürü olarak hareket eden sığırlar birbiriyle göz temasını korur ve böylelikle sürü koordineli bir bütün olarak hareket edebilir.

Denge noktası sığırın bir yerden bir yere sürme (ileriye doğru hareket) veya hareketine son vermesi (durması) istendiğinde durulacak pozisyonu göstermektedir.

Şekil 1'de "A" harfi ile gösterilen yerde durulduğunda sığır dur emrini almış olacak ve duracaktır. Ancak, "B" harfi ile gösterilen noktada durulduğunda ise sığır bu sefer ileriye doğru git (hareket) emrini almış olacak ve gidecektir. A ve B noktaları çok yakın noktalar olmasına rağmen birinde dur diğerinde ise git emri algılaması "bireysel güvenlik bölgesi”" sınırları ile alakalıdır. "A noktası", bireysel güvenlik bölge sınırı dışını, "B noktası" ise bireysel güvenlik bölgesi sınırı içini göstermektedir (Grandin, 1989). Ancak bu hareketlerde ani, hizlı veya sert hareketler yapılmaması çok önemlidir. Sakin, güvenli ve rahat adımlarla, ineğin görebileceği ve anlayabileceği süre bırakılarak hareket edilmesi gerekir. Eğer bir sığır sürüsü içine girilirse sürüdeki sığırlar size dönük duruyorlarsa bireysel emniyet bölgesi dişında bulunuyorsunuz demektir. Hayvanlar kendilerini güvende hissettiği bu mesafeyi, her zaman korumaya çalışacaklardır. $\mathrm{Bu}$ amaçla yaklaştığınızda kaçma, uzaklaştığınızda da yaklaşma eğiliminde olacaklardır. 


\section{Sürünün Yönetimi}

Sığır sürü hayvanı olup ön tarafta bir sığır görecek olursa ilerlemesi kolaylaşır. Sürü halinde hareket eden sığırın bir kapıdan geçmesi gerekiyorsa bakıcının "sürü güvenlik bölgesi" sinırında durması yeterli olacaktır. Ancak eğer sığır hareket etmeyi keserse bu bölgeye girmelidir. Bakıcılar tarafindan sıklıkla yapılan yanlış, hayvanlara kaçış yolu bırakmadan, kolektif güvenlik bölgesinde durmaktır. SGB sinırlarına fazla giriş sığırın geri dönüp sürüden ayrılmalarına neden olmaktadır.

\section{Hayvan doğasına uygun alet ekipmanlar}

$\mathrm{Bu}$ işlemler sırasında hayvanlarda yara bereler ile çalışanlarda yaralanmalarda sıklıkla yaşanan problemler arasında yer almaktadır. Hayvancılık çalışanları hayvanları yönlendirmek için genel olarak vurmak, zorlamak, sopa kullanarak bağırmak ve elektrik şoklarını kullanmaktadırlar. Elektrik şoklar ilk anda şiddetli hareket verse de hayvanlarda kalıcı öğrenme ile daha sonraki işlemlerde zorluğun artmasına neden olmaktadır. Bununla birlikte, elektrikli uyarıcılar ancak doğru kullanıldığı takdirde faydalı bir yardımcıdır. Elektrikli uyarıcı gidecek hiçbir yeri olmayan veya halihazırda sürüde doğru yönde hareket eden bir hayvan üzerinde kesinlikle kullanılmamalıdır. Bunların yerine, plastik veya gazete, bayraklı çubuklar gibi yardımcılar kullanılabilir. Bir sığırın önünde bir sopa tutmak, durmasına veya dönmesine neden olacaktır. Ancak sopayı hayvana vurmak için kullanmak hayvanları doğru yönde hareket ettirmede gereksiz ve etkisizdir. Zaten doğru yönde hareket eden bir hayvanı dürtmek sığırların tekmelemesine neden olacağı için tehlikelidir.

\section{Hayvan koridorları kullanımı}

Genel olarak ahırların inşası ve ahır bölmeleri arası geçiş sağlayan koridorların, sığırların doğal davranışını sağlayacak veya bu doğal davranışı dikkate alacak şekilde tasarlanması gerekir. Kötü tasarlanmış tesisler, sı ğırlarda strese neden olarak hem hayvan hem de çalışanların yaralanma riski artar (Huhnke ve Harp 1998; Smith, 2002). Tesis tasarımının temel elemanı doğru hayvan akışı sağlamaktır. Tesis büyüdükçe tesisin doğru tasarlanmasının önemi daha da artar. Ayrıca sığırlar çok çabuk öğrenen hayvanlar olup işlem yapılan bir yere (tartım olsun diğer işlemler olsun) çabuk alışılar. Her seferinde aynı şekilde muamele edilirse sığır öğrenecek ve akış kolaylaşacaktır. Ayrıca sığır sürü hayvanı olmasına rağmen aşırı kalabalık ve sıkışık alanları da sevmez bu nedenle çalışma alanlarının aşırı kalabalık tutulmasina dikkat edilmelidir. Hayvanlarla çalışırken kullanılan bölmelerin tamamını doldurmak yerine yarım dolu olarak çalışmak hayvana rahat hareket etme şansı verdiğinden daha rahat iş ortamı sağlar. Ayrıca hayvanla çalışırken kullanılan bölmelerde, sığır hareketine yer kalması açısından çok fazla bakıcı bulunmamalıdır.

Ne yazık ki, uygulamaya bakıldığında durum böyle değildir. Sığırların doğal davranışını sağlamayacak kötü tasarlanmış ahırlarda çalışmak yapılacak işlerin zorlaşmasına, stresin artmasına ve yapılacak işin süresinin uzamasına neden olmaktadır. Sığırlar, büyük bir alandan küçük dar bir alana doğru gitmek istemezler. $\mathrm{Bu}$ nedenle sığır padoklarının genişten dara doğru eğimle daraltılması hareketi kolaylaştırır. Ayrıca sığırlar önlerinde bir açıklık veya boşluk görebiliyorsa daha kolay girerler. Bu nedenle sığır bir bölme veya sıkıştırma yerine alınacaksa giriş yönünde açıklık bırakmak hareketi kolaylaştırır. Koridorların özellikle hayvan akışının durduğu sıkışmaların yaşandığ 1 noktalarda hareketi uyarıcı işaret bayraklarının kullanılması sığırların daha kolay akmasını sağlayabilir. Koridor ve padokların dış tarafına dikkat dağıtıcıların yanı sıra, hayvanlara yön gösterecek sinyaller, kullanılabilir.

\section{İyi Bakıcı}

İyi bir hayvan bakıcısı, hayvan davranışları veya görünümlerinde ki kü̧̈ük farklılıkları fark edebilen, sakin, kesin ve düzenli hareketlerle hayvan yaklaşmayı bilen olmalıdır. Çünkü sığırlar ani, hızlı ve düzensiz yaklaşımlarda stres olmakta ve bu stres etmenine karşı tepki vermektedirler (Gahan ve Johnston, 1988; Hubert ve ark, 2003). 
Bakıcılar için istenen özellikler hayvanlara karşı olumlu bir tutumdur. Hayvan davranışını anlama; hayvan eylemlerini tanıma ve yorumlama becerisi ve işlemler için sabırla acele etmeden hayvanın koşullarına uyumu yeterli zamanın tanınması güvenli iş yapma becerisi açısından avantajlıdır. Sı ğırların bir yerden bir yere taşınması sırasında yaralanmaları engellemek için her zaman gözlerin hayvanların üzerinde olması lazımdır. Bakıcıların bir anlık dikkatinin başka bir yere kayması yaralanma riskini artırır (Nordstrom ve ark. 1995; Murphy ve ark. 2016; Zhou ve Roseman.1994).

Herhangi bir saldırıya karşı hayvanlarda, korku veya sıkıntı işareti olan belirtileri yakından izlemek gerekir. Sığırda saldırı hali belirtileri olarak kuyruk hareketleri, göz beyazlarının ortaya çıkması, alarm haldeki baș yapısı, endișeli kulak duruşu, artan dışkılama, gevşek gübre, deri titremesi, soluma hızının artışı sayılabilir.

Bir hayvan bu belirtilerin bir veya birkaçını gösterirse yapılacak en iyi șey, hayvanı hareket ettirmeden önce sakinleșene kadar beklemektir.

\section{Hayvana Yaklaşım Değerlendirme}

Bir işletmede hayvanlara bakım ve diğer uygulamalar sırasında nasıl yaklaşıldığı puanlanarak işletme risk puanı çıkarılabilir. "Kayma ve düşme sayısı" hayvanlara bakım ve uygulamalar sırasındaki refahın önemli bir ölçüsüdür, çünkü hayvanların dengelerini kaybetmelerinin bir sonucudur. Ayrica hayvan koridorlarında hayvanlar taşınırken kayan hayvan sayısı ve yüzdesi de bir diğer stres göstergesidir. Eğer bu aşamada çalışanlar hayvanlar normal yürürken de müdahale ederse veya bir hayvanın davranışsal olarak ajite edilmesine neden olursa "kayma sayısı "artar. Uygulamalar sırasında herhangi bir alanda "düsşen hayvan sayısı" da yanlış yaklaşım göstergesidir (Grandin, 1998). Kayma ve düşme her hayvan için bağımsız olarak puanlanır. Kalabalık hayvan bekleme bölmesinde, koridorlarda veya bölmelerdeki düşen hayvan sayıs1 tespiti yapılır. "Elektrikli uyarıcı kullanımı" hayvan refahını olumsuz etkileyen ve stresi artıran bir uygulamadır ve işlemler sırasında kaç kez ve hangi durumlarda kullanıldığının belirlenmesi gerekir. Çünkü tekrarlanan "elektrikli uyarıcı kullanımı" sıklığı hayvanlarda böğürme ve saldırgan davranış1 tetiklemektedir. Sığır genelde sürü içinde vücut dili anlaşan bir türdür. Ancak uzaktaki bireylerle iletişim için sesi kullanır. Ancak yapılan uygulamalarda sürü içinde "seslilik artmış" özelikle böğürme tarz ses çok ise yüksek stres belirtisidir

\section{Sonuc}

Hayvanlarda davranış özellikleri ve mizaç genetik yapı ile ilişkilidir. Ancak uygunsuz veya stresli, kötü muamele sakin bir hayvanı da saldırgan yapabilir. Sığırlar kendine kötü davranan kişileri ve yeri hatırlar ve gelecekte benzer bir durumdan kaçınmak için uğraşır. İşletmelerde yapılan uygulamalar sirasında yaşanan stres düzeyi düşme, sık idrar yapma, kayma, seslilik, elektrikli uyarıcı kullanımı gibi göstergelerle tahmin edilebilir. Bugüne kadar işletmelerde yapılan gözlemler vurma, bağırma ve elektrikli uyarıcı kullanımın çok yaygın olduğunu göstermektedir. Oysa, sığırların dünyayı nasıl gördükleri ve algıladıklarını bilerek yaklaşmak stressiz sürü yönetimini mümkün kılmaktadır. Hayvansal temas kaynaklı yaralanmalar hafiften şiddetliye değişen düzeylerde kayıplara neden olmaktadır. Yaralanma sonrası, tedavi masrafları ve iyileşme süreci ise etkiyi artırmaktadır. $\mathrm{Bu}$ konuda eğitim almamış kişilerin çalışma zorunluluğu ve farklı alanlardan kişilerin hayvancilıkta istihdamı konuları stresi daha da artırmaktadır. Bu nedenle hayvancılık işletmelerinin çalışanlarına hayvan davranışları ve sürü yönetimi konusunda hizmet içi özel eğitim vermesi verimlilikte ve kayıpları önlemede önemli bir basamak olacaktır.

\section{Kaynaklar}

Albright, J., 2004. Improving animal welfare of dairy cows through management. http://www.

İnform.umd.edu/EdRes/Topic/AgrEnv/n dd/business/IMPROVING_THE_WELF ARE_OF_DAIRY_COWS.html 
Anonim, 2016. Occupational Safety and Health (OSHA): Quick Facts. https://www.osha.gov/dsg/topics/ agriculturaloperations (accessed 1 Feb 2017).

Anonim, 2016. Occupational Safety and Health (OSHA): Quick Facts. https://www.osha.gov/dsg/topics/ agriculturaloperations (accessed $1 \mathrm{Feb}$ 2017).

Anonim, 2019. Working the Flight Zone. https://www.hihog.com/resources/livestock-handlingtips/working-the-flight-zone/

Breuer K, Hemsworth PH, Barnett JL, Matthews LR, Coleman GJ., 2000. Behavioural response to humans and the productivity of commercial dairy cows. ApplAnimBehav Sci. 2000 Mar 1;66(4):273-288.

Busch Jr HM, Cogbill TH, Landercasper J, 1986. Blunt bovine and equine trauma. $\mathbf{J}$ Trauma 1986;26(June (6)):559-60.

Conrad L. 1994. The maul of the wild: animal attacks can produce significant trauma. Emerg Med Serv 1994;23(March (3)):71-2. 76.

Gahan RJ \& Johnston BD 1988. Handling Cattle from Farm to Abattoir. Bulletin, NSW Agriculture, Orange Department of Agriculture New South Wales, 1988.

Göncü, S., 2018. Sığır Davranışları ve Sürü Yönetimi. Akademisyen Kitabevi A.Ş. 2018, 151 sf.

Göncü, S., Koluman, N., 2019. Çifliklerde hayvanla temas kaynaklı yaralanmalar ve önleme yolları. 1. Uluslararası Erciyes Tarım, Hayvancilık ve Gida Bilimleri Konferansi'n1 (AgAnFoS2019). 24-27 Nisan 2019.

Göncü,S., Türkoğlu, G., Önder, D., Koluman, N., 2017. Risk Factors for Animal Related Injury Among Livestock Farmers. International Conference on Agriculture, Forest, Food Sciences and Technologies (ICAFOF 2017). Cappadocia, Nevsehir, Turkey, May 15 17, 2017 sf.111.

Grandin, T. 1989. Behavioral Principles of Livestock Handling. Professional Animal Scientist, December, pp. 1-11. Kilgour R., and D.C. Dalton. 1984.
Livestock Behaviour, A Practical Guide. Collins Technical Books, Glasgow, United Kingdom.

Grandin, T. 1993. Livestock Handling and Transport. 2nd Edition (Ed. T. Grandin), CAB International, Wallingford Oxon, United Kingdom.

Grandin, T. 1998. Objective scoring of animal handling and stunning practices at slaughter plants. https://www.grandin.com/references/sco ring.ab.html

Hediger, Heini (1955). Studies of the psychology and behaviour of captive animals in zoos and circuses. London: Butterworths Scientific Publications. ASIN B0007IXEUS. (German edition: Zirich, Buechergilde Gutenberg, 1954)

Hemsworth P.H., Coleman G.J., Barnett J.L., Borg S., 2000. Relationships between human-animal interactions and productivity of commercial dairy cows. J Anim Sci. 2000 Nov; 78(11):2821-31.

Hubert, D.J., Huhnke, R.L. \& Harp, S.L. (2003). Cattle handling safety in working facilities. Available from: http://pods.dasnr.okstate.edu/docushare/ dsweb/Get/ Document- 4821/BAE1738web.pdf

Huhnke R.L., Harp S., 1998. Corral and Working Facilities for Beef Cattle. http://pods.dasnr.okstate.edu/docushare/ dsweb/Get/Document-1998/F1219web.pdf

Kilgour, R., (1971). Animal handling in works, pertinent behaviour studies. 13th Meat Industry Research Conference, Hamilton, New Zealand. pp. 9-12.

Langley, R.L., Hunter, J.L. (2001). Occupational fatalities due to animalrelated events. Wilderness Environ Med, Vol. 12, pp. 168-174

Lindahl, C., Pinzke, S., Herlin, A., Keeling L.J., 2016. Human-animal interactions and safety during dairy cattle handlingComparing moving cows to milking and hoof trimming. Journal of Dairy Science, Volume 99, Issue 3, March 2016, Pages 2131-2141

Lindsay S, Selvaraj S, Macdonald JW, 2004. Injuries to Scottish farmers while tagging and clipping cattle: a cross- 
sectional survey. Occup Med (Lond) 2004;54(March (2)):86-91.

Murphy, C. G., McGuire, C.M., O'Malley, N., Harrington, P., 2016. Cow-related trauma: A 10-year review of injuries admitted to a single institution. Injury, Int. J. Care Injured 41 (2010) 548-550

Nogalski, A., Jankiewicz, L., Cwik, G., Karski, J. \& Matuszewski, L. (2007). Animal related injuries treated at the Department of Trauma and Emergency Medicine, Medical University of Lublin. Ann Agric Environ Med, Vol. 14, pp. 57-61

Nordstrom, D.L., Layde, P.M., Olson, K.A., Stueland, D.T., Brand, L. \&Follen, M.A. (1995). Incidence of farm-work-related acute injury in a defined population. Am J Ind Med, Vol. 28, pp. 551-554

Ornehult L, Eriksson A, Bjo“rnstig U. 1989. Fatalities caused by nonvenomous animals: a ten-year summary from Sweden. Accid Anal Prev 1989;21(August (4)):377-81.

Panea B, Ripoll G. 2918. Quality and Safety of Meat Products. Foods. 2018 Jul 26;7(8):118.

doi:

10.3390/foods7080118. PubMed PMID: 30049939; PubMed Central PMCID: PMC6111319.

Pickett W, Brison RJ, Niezgoda H, Chipman ML., Nonfatal farm injuries in Ontario: a population-based survey.Accid Anal Prev. 1995 Aug;27(4):425-33.

Smith, K.L. 2002. Cattle Handling and Working Facilities. https://agnr.osu.edu/sites/agnr/files/imce /pdfs/Beef/CattleFacilities.pdf

Sprince NL, Park H, Zwerling C, 2003. Risk factors for animal-related injury among Iowa large-livestock farmers: a casecontrol study nested in the Agricultural Health Study. J Rural Health 2003;19(Spring (2)):165-73.

Wiggins, P., Schenker, M.B., Green, R. \& Samuels, S. (1989). Prevalence of hazardous exposures in veterinary practice. Am J Ind Med, Vol. 16, pp. 5566

Zhou, C. ve Roseman, J.M. (1994). Agricultural injuries among a population- based sample of farm operators in Alabama. Am J Ind Med, Vol. 25, pp. 385-402 